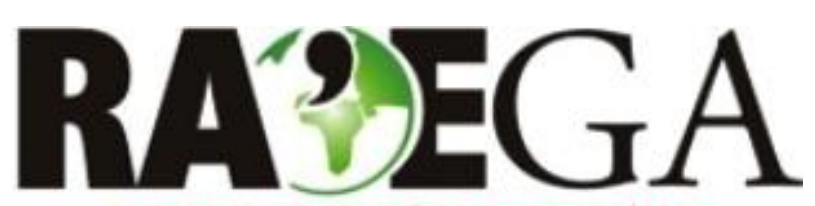

O ESPACYO GEOGRÁFICO EM ANÁLISE

\title{
REDE URBANA E NOVAS INTERAÇÕES ESPACIAIS EM CIDADES MÉDIAS: UMA ANÁLISE ACERCA DO FLUXO AÉREO NO AEROPORTO MÁRIO RIBEIRO EM MONTES CLAROS/MG
}

\section{URBAN NETWORK AND NEW SPATIAL INTERACTIONS IN MEDIUM CITIES \\ AN ANALYSIS OF THE AIRFLOW AT MARIO RIBEIRO AIRPORT - MONTES CLAROS/MG}

\author{
lara Soares de França \\ Professora do Programa de Pós Graduação em Geografia em \\ Sociedade, Ambiente e Território \\ Universidade Estadual de Montes Claros - UNIMONTES \\ Montes Claros, MG, Brasil \\ e-mail: isfufu@yahoo.com.br \\ Maria Ivete Soares de Almeida \\ Professora do Departamento de Geociências \\ Universidade Estadual de Montes Claros - UNIMONTES \\ Montes Claros, MG, Brasil \\ e-mail:ivetegeo@yahoo.com.br
}

Recebido em: 30/05/2015

Aceito em: 27/10/2015

\section{Resumo}

Este artigo analisa a centralidade exercida pela cidade média de Montes Claros/MG a partir dos fluxos aéreos no Aeroporto Mario Ribeiro, diagnosticados nos anos de 2013 e 2014. Destaca-se Montes Claros/MG no contexto das cidades médias brasileiras assumindo um papel de grande relevância nas redes urbanas quanto a sua crescente dinâmica e consolidação. Trata-se de uma cidade média que, ao final do século $\mathrm{XX}$, apresenta transformações socioespaciais relacionadas à atração de capitais, bens, serviços, mercadorias, infraestruturas e pessoas. Com o adensamento das atividades econômicas, produtivas e as interações espaçais existentes, Montes Claros configura-se como uma importante centralidade em escala regional e inter-regional contextualizando o surgimento de novas interações espaciais e a consolidação das interações já existentes, tais como a dinamização industrial e a procura por comércios atacadistas e varejistas e serviços especializados em 
educação superior e técnica, além da rede de saúde de alta complexidade. Nesse sentido, essa cidade média amplia a sua centralidade ao encabeçar a rede de conexões aéreas no Norte de Minas, denotando sua expressão como nó articulador das interações na rede urbana nas escalas intra e inter-regional. Com isso, expande também o seu papel articulador, demonstrando a sua crescente especialização funcional e outras formas de inserção na rede urbana.

Palavras-chave: Centralidade; intra e inter-urbano; setor aéreo; fluxos e fixos; Norte de Minas

\begin{abstract}
This article analyzes the centrality exercised by the medium city of Montes Claros regarding the airflow at Mario Ribeiro Airport observed in 2013 and 2014. Montes Claros stands out among the Brazilian medium cities playing a relevant role related to its growing dynamics in urban networks. Montes Claros is a medium city that presents socio-spatial transformations related to attracting capital, goods, services, infrastructure and people. It appears as an important centrality in regional and inter-regional scale consolidating economic and productive activities as well as the existing spatial interactions such as industrial promotion and the search for wholesale and retail business, specialized services in higher and technical education, in addition to highly complex health care system. Accordingly, this medium city expands its centrality by managing the air traffic connections in the North of Minas Gerais highlighting its importance as a coordinator of the interactions in the urban network for intra and inter-regional scales. Thus, Montes Claros presents an increasing functional specialization and other forms of integration into the urban network.
\end{abstract}

Keywords: Centrality; intra and inter-urban; aerial sector; flows and fixed; North of Minas

\title{
1. INTRODUÇÃO
}

$\mathrm{Na}$ Geografia o estudo das cidades nas mais diversas abordagens tem se tornado cada vez mais necessário. Em primeiro lugar pelo fato deste ser 0 espaço onde vive a maior parte da população em vários países do mundo. $E$ não menos importante, pela dinâmica interna, a posição na rede urbana, os problemas e alternativas de gestão que representam um amplo campo para pesquisas teóricas e empíricas.

As cidades médias têm grande importância na estruturação do território. Constituem elementos importantes no contexto da urbanização contemporânea e ganham importância, tanto em termos de organização e articulação dos espaços regionais, quanto em termos políticos e econômicos. Esses centros 
urbanos dotados de potencialidades atraem para seu espaço interno e regional capitais econômicos, tecnologias, indústrias e fluxos populacionais.

Pesquisas recentes procuram não somente classificar, conceituar ou definir tais espaços, mas compreendê-los em sua totalidade. Com isso, os estudiosos consideram outros critérios não restritos apenas ao tamanho demográfico, tais como: tamanho populacional, urbanidade, potencial econômico, infraestrutura, consumo, rede urbana e qualidade de vida são fatores relevantes no estudo das cidades médias.

Spósito (2001) aborda a importância da análise de como se estabelece no território a divisão regional do trabalho e como a cidade média comanda esse território. Dessa maneira,

\begin{abstract}
[...] a definição de cidade média tem por base as funções urbanas da cidade, relacionadas, sobretudo, aos níveis de consumo e ao comando da produção regional nos seus aspectos técnicos. Já não é mais um centro no meio da hierarquia urbana, mas, sim, uma cidade com capacidade para participar de relações que se estabelecem nos sistemas urbanos nacionais e internacionais. Os estudos sobre essas cidades devem estar calcados numa concepção, em rede, da cidade e da região, numa perspectiva que priorize, mais que a dimensão demográfica, o modo como a cidade média articula as suas relações com os demais componentes do sistema urbano. (PEREIRA, 2005, p.1).
\end{abstract}

As cidades médias representam importantes centros econômicos e demográficos, redefinindo novos papéis frente a recente organização territorial brasileira. As atuais dinâmicas de consumo e produção que se estabelecem nos espaços intra e inter-urbanos dessas cidades influenciam e são igualmente condicionadas pelos novos arranjos territoriais e econômicos relativos a produção e consumo do espaço urbano.

O papel de intermediação exercido pelas cidades médias ocorre através das trocas comerciais, de serviços ou de pessoas com a sua hinterlândia e com uma área metropolitana. Isso evidencia, notadamente, a relevância regional que as cidades médias adquirem através da interação exercida com os centros urbanos menores, as zonas rurais, distritos e vilas, ou seja, a região de influência próxima. Pois, as cidades médias são importantes nós de intermediação dentro de uma rede urbana.

Corrêa (2007, p.27-29) reforça a relevância de estudos nessa temática: 
Acreditamos que a relevância de qualquer tema derive da capacidade do pesquisador em problematizá-lo, de transformá-lo em uma questão teórica ou empírica, visando quer a uma ação prática, quer a compreensão de um ou mais aspectos associados à ação humana.

Nesse sentido, este artigo ${ }^{1}$ analisa a centralidade exercida pela cidade média de Montes Claros/MG a partir dos fluxos aéreos no Aeroporto Mario Ribeiro da Silveira, diagnosticados nos anos de 2013 e 2014. Montes Claros possui elevada importância regional ao encabeçar a rede de conexões aéreas no Norte de Minas. O aeroporto atende toda a população do Norte de Minas, pois é o único da região, de forma que todas as pessoas que utilizam este tipo de transporte dependem de Montes Claros, remetendo novamente a sua centralidade nesse setor, o transporte aéreo.

\section{MATERIAIS E MÉTODOS}

Para o desenvolvimento da pesquisa identificou-se o fluxo aéreo no período de 2013 e 2014 e, com isso, a sua importância para a análise de Montes Claros na rede urbana. A pesquisa documental realizou-se no sítio eletrônico da Infraero o que permitiu conhecer o fluxo mensal de passageiros (embarque e desembarque), bem como, o movimento de pousos e decolagens.

Foram aplicados questionários aos passageiros no aeroporto Mário Ribeiro, em Montes Claros/MG nos dias 13 e 18 do mês de novembro de 2013. As perguntas versavam sobre a origem e o destino dos passageiros e também as motivações dos deslocamentos. Os questionários foram aplicados observando-se separadamente as pessoas que chegavam ao aeroporto para utilizar o terminal e as pessoas que chegavam dos voos de outros terminais aeroviários.

Após a aplicação dos questionários, os dados foram sistematicamente contabilizados no programa Microsoft Excell® e, posteriormente, representados na forma de tabelas, gráficos e mapas. O mapa de fluxo e intensidade foi

\footnotetext{
${ }^{1}$ Este artigo resulta da pesquisa $A$ Rede Urbana Norte-Mineira: consolidação, dinâmicas recentes e refuncionalização (1950 a 2010), financiada pela Fundação de Amparo à Pesquisa do Estado de Minas Gerais/FAPEMIG, desenvolvida pelos autores no Laboratório de Estudos Urbanos e Rurais/LAEUR, vinculado ao Departamento de Geociências da Universidade Estadual de Montes Claros/UNIMONTES.
} 
elaborado no software ArcGis $(B)$ 10.0, obedecendo-se aos critérios cartográficos, da seguinte maneira: os dados de origem dos dias 13 e 18 foram cruzados e somados, originando uma tabela. O mesmo foi feito com os dados de destino. Com isso, foi elaborada a base cartográfica (shapefile) identificando o destino dos passageiros que embarcaram e a origem dos passageiros que desembarcaram no aeroporto de Montes Claros-MG.

Os dados de intensidade foram sistematizados no software ArcGis, dando origem a mapas, nos quais as origens e destinos dos passageiros foram representadas por linhas/setas de conexão entre municípios e a intensidade dos fluxos definidas por largura e cor das linhas/setas. No mapa foi necessária a adequação ao layout de uma folha $A 4$.

A análise realizada pautou-se nas temáticas: redes urbanas, cidades médias, centralidade e fluxos aéreos.

\section{RESULTADOS E DISCUSSÃO}

\subsection{As cidades médias como centros articuladores das redes urbanas}

As cidades médias, objeto de estudo de pesquisadores da geografia urbana, notadamente, tornam-se cada vez mais dinâmicas do ponto de vista espacial, demográfico e econômico. A sua análise no contexto brasileiro relaciona-se, entre outras razões, a iniciativas de estado.

$\mathrm{Na}$ década de 1970, o governo federal brasileiro, por meio de políticas de desconcentração metropolitana que tinham como finalidade propiciar um equilíbrio urbano dando uma nova alternativa para os fluxos migratórios que se direcionavam para São Paulo, Rio de Janeiro, Belo Horizonte, incentivou a criação de novos polos de desenvolvimento em espaços não metropolitanos ${ }^{2}$.

\footnotetext{
${ }^{2}$ Um dos incentivos resultou do II Plano Nacional de Desenvolvimento Econômico e Social - II PND em 1975. O Programa Nacional de Apoio às Capitais e Cidades de Porte Médio PNCCPM parte integrante do II PND na década de 1970 identificou as cidades médias brasileiras, a fim de realizar investimentos em infraestrutura, urbanização, transporte e dinamização econômica. O referido programa viabilizou o desenvolvimento das cidades médias que com a intervenção do estado nesse contexto começaram a exibir um crescimento demográfico e econômico expressivo. Uma das cidades beneficiadas no país com esse programa foi Montes Claros, a única no Norte de Minas Gerais, melhorando assim sua infraestrutura e atraindo diversas indústrias, com os planos de incentivos fiscais, desenvolvendo assim a sua economia. (FRANÇA, 2007). Incluído na área mineira da
} 


\title{
REDE URBANA E NOVAS INTERAÇÕES ESPACIAIS EM CIDADES MÉDIAS: UMA ANÁLISE ACERCA DO FLUXO AÉREO NO AEROPORTO MÁRIO RIBEIRO EM MONTES CLAROS/MG
}

Um dos principais elementos de análise das cidades médias refere-se à centralidade que exercem na rede urbana em que se inserem. A força de articulação com outros centros urbanos; o poder de atuação como centro principal de oferta de serviços, comércio, moradia e emprego, entre outros bens, para a sua área de influência; mostra a relevância de uma determinada cidade no seu contexto regional e em outros níveis e escalas urbanas.

Tal argumentação encontra sustentação em Spósito (2007, p.7) que ratifica: "A importância de uma cidade média tem relação direta com a área de influência, ou seja, a área a partir da qual alguém está disposto a se deslocar até uma cidade média para nela ter acesso ao consumo de bens e serviços".

As cidades na contemporaneidade resultam de profundas mudanças nos processos de industrialização e urbanização. Para Santos (2008), esse contexto inaugura novas características da urbanização na recente economia internacional, especialmente nos países subdesenvolvidos.

\begin{abstract}
A nova economia internacional, que se manifesta depois da Segunda Guerra Mundial, apresenta, entre outras, as seguintes características: internacionalização e multiplicação das trocas, preponderância da tecnologia e a concentração dela decorrente, solidariedade crescente entre os países (cooperação entre países industriais, domínio sobre os países subdesenvolvidos), modificações da estrutura e força do consumo. (SANTOS, 2008, p.23).
\end{abstract}

Como efeito direto dessas transformações, têm-se novos arranjos territoriais e espaciais no âmbito intra e inter-urbano das cidades, o que remete as novas dinâmicas das redes urbanas.

Geiger (1963, p. 435-436) descreve a importância da industrialização para a organização das redes urbanas e da posição hierárquica das cidades.

A influência do processo de industrialização é o principal aspecto da
mais recente fase da evolução urbana que se caracteriza na
aceleração do ritmo de crescimento da população urbana, no sentido
absoluto e relativamente à população total do País, formação das
aglomerações mais complexas e agigantadas das grandes

Superintendência de Desenvolvimento do Nordeste - SUDENE em 1965, o município passou por diversas transformações demográficas, econômicas, políticas e sociais. A cidade se industrializou rapidamente e atraiu um grande contingente populacional, fruto das migrações que a ela se dirigiu oriundas de outros municípios do Norte e Nordeste do estado, bem como do Sul da Bahia. Assim, Montes Claros foi palco de programas de investimentos públicos financiados pelo Estado e pela União para a sua configuração como polo de desenvolvimento. 


\section{REDE URBANA E NOVAS INTERAÇÕES ESPACIAIS EM CIDADES MÉDIAS: UMA ANÁLISE ACERCA DO FLUXO AÉREO NO AEROPORTO MÁRIO RIBEIRO EM MONTES CLAROS/MG}

metrópoles, transformação de velhos núcleos urbanos ou de localidades que anteriormente tinham outra função, em centros industriais; aparecimento de novos centros urbanos de atividade industrial e maior hierarquização dos centros. A industrialização de cidades de tamanho médio consolida a sua posição como capitais regionais, ou como centros de categoria elevada. A especialização de funções, outro aspecto da estrutura urbana mais recente, se, em parte, não decorre diretamente da industrialização, certamente resulta da existência de uma sociedade mais complexa. A industrialização influi no crescimento urbano através da ampliação do setor terciário, em função desta mesma industrialização.

Considerando o urbano como forma e a urbanização como processo dele decorrente, Matos (2005) relata a indissociabilidade de ambos - base para a construção das redes urbanas

Se o urbano é complexo, supõe centralidades, funções, tamanho, hierarquias, representatividade diante das hinterlândias - o que evoca as territorialidades regionais ou sub-regionais; passa a ser oportuno pensar na urbanização como um processo socioespacial ancorado por conexões geográficas que articulam pontos especiais (cidades ou áreas urbanas) distribuídos no território. Estruturas que conformam redes, redes urbanas. (MATOS, 2005, p.39).

Cada época revela novos elementos ao estudo das redes urbanas. Os atuais processos espaço-temporais aliados à produção e reprodução das cidades redefinem a importância das redes urbanas não somente no plano acadêmico-científico quanto às relações de interdependência dos centros hierarquizados, mas também enquanto instrumento de planejamento urbano.

O conceito de rede urbana evolui no espaço e no tempo, isto é, com a emergência de diversos acontecimentos, sobretudo, a industrialização, a urbanização e, atualmente, a globalização. É o que reitera Corrêa (2006, p.15)

Os investimentos, pensados e programados segundo uma perspectiva global, criaram e reestruturaram inúmeras e complexas redes geográficas das quais a rede urbana é a expressão mais contundente. Trata-se, em toda parte, de uma rede urbana impactada pela globalização, na qual cada centro, por minúsculo que seja, participa ainda que não exclusivamente, de um ou mais circuitos espaciais de produção (Santos, 1988), produzindo, distribuindo ou apenas consumindo bens, serviços e informações que, crescentemente, circulam por meio da efetiva ação de corporações globais.

É durante o processo da urbanização que a rede urbana se constitui e passa a ser o meio através do qual produção, circulação e consumo se realizam efetivamente. Fica claro então que a formação das redes urbanas associa-se as 
especificidades econômicas, históricas e culturais de cada país associadas às características da urbanização contemporânea.

No âmbito acadêmico científico, a análise referente às redes urbanas explica a relação de interdependência entre diversos tipos de cidades, as funções que as mesmas desempenham, configurando as redes urbanas tanto em escalas globais como nacionais ou regionais. Assim, uma rede urbana, quando constituída, reflete a expansão e oferta de produtos, serviços e bens além de a forma de ocupação e apropriação dos espaços intra e inter-urbanos.

O papel dos sistemas de transportes foi discutido por Beaujeu-Garnier (1997, p.476) como elemento fundamental na estruturação das redes urbanas
O estudo dos transportes tem um significado muito importante e dá uma imagem da intensidade das relações de uma cidade com o seu meio. É necessário ter em consideração o desenho da rede e a intensidade da circulação que dá a melhor imagem possível da influência regional de uma cidade: é a imagem exacta das relações de uma cidade com o seu meio.

Corrêa (2006, p.27) faz referência à ação de agentes sociais diversos na materialização das redes urbanas

\begin{abstract}
A rede urbana é um reflexo, na realidade, dos efeitos acumulados da prática de diferentes agentes sociais, sobretudo as grandes corporações multifuncionais e multilocalizadas que, efetivamente, introduzem, tanto na cidade como no campo, atividades que geram diferenciações entre os centros urbanos. Diferenciações que, por sua vez, condicionam novas ações.
\end{abstract}

Sendo assim, apreende-se que as redes urbanas se formam a partir de inúmeros elementos associados entre si. De um lado, tem-se uma rede de cidades interligadas num dado território compartilhando de uma dinâmica espacial e territorial. Soma-se a isso, o peso populacional das localidades urbanas e os deslocamentos entre os municípios que se processam através da articulação via sistemas de transportes e meios de comunicação. O papel dos agentes econômicos, políticos e sociais como produtores do urbano traduzem a concretização das redes urbanas como reflexos e condicionantes sociais, argumentação exposta por Corrêa (1997).

A articulação ou as trocas estabelecidas entre as cidades pode ser interpretada através da centralidade. Seu estudo é bastante frequente nas 
pesquisas sobre redes urbanas. As cidades da rede urbana são as localidades centrais que exercem a centralidade, nesse caso a centralidade urbana.

A Teoria das Localidades Centrais ou da Centralidade ${ }^{3}$ formulada por Christallher na década de 1930 incorporou os conceitos de localidades centrais e centralidade.[...] o conjunto de centros de uma região ou país - cidades, vilas, povoados e estabelecimentos comerciais isolados na zona rural - em seu papel de distribuição varejista e de prestação de serviços para uma população neles residente. Estes centros são denominados localidades centrais ea centralidade de que dispõem é derivada de seu papel como centros distribuidores de bens e serviços, ou seja, das funções centrais que desempenham. Trata-se, portanto, de uma teoria que, de acordo com sua formulação original, seleciona para análise um dos múltiplos papéis que as cidades e núcleos de povoamento desempenham. (REGIC, IBGE, 1987, p.11)

Sobre a emergência de centralidades, Lefebvre (1999) acrescenta

A cidade atrai para si tudo o que nasce, da natureza e do trabalho, noutros lugares: frutos e objetos, produtos e produtores, obras e criações, atividades e situações. O que ela cria? Nada. Ela centraliza as criações, sem aproximação, sem proximidades, isto é, sem relações. (LEFEBVRE, 1999. p.42).

As ideias desenvolvidas por Christallher (1966) e Lefebvre (1999) demonstram que uma cidade destaca-se ao oferecer maior diversidade de bens e serviços no sistema urbano em que se insere, sendo que para o primeiro as cidades se tornam hierarquicamente centrais em relação às demais pela sua capacidade de concentrar e centralizar.

Whitacker (2007) discorre a respeito da centralidade na escala interurbana como elemento fundamental à compreensão das redes urbanas.

Essa centralidade também não se define apenas no nível intraurbano, mas na articulação de diferentes níveis e escalas, sobretudo quando não se restringe a elaboração do modelo teórico à concepção de hierarquia urbana tradicional, mas sim se compreende a constituição de redes num padrão não necessariamente concêntrico e que possui articulações definidas por fluxos. Portanto, não apenas a definição da centralidade no tecido urbano se dá pelos fluxos e é dinâmica, mas também a centralidade pensada na escala da rede, ambas podendo, conforme características e tempos, sobreporem-se.

Para se compreender a concepção de centralidade, o autor propõe:

${ }^{3}$ CHRISTALLER, W. Central Places in Southern Germanny, Prentice-Hall Inc., Englewood Cliffs, 1966. 
[...] são os fluxos os elementos determinantes, muito mais que a localização. Esses fluxos são incrementados pelas comunicações e telecomunicações que são traduzidas em trocas, decisões, gestão, controle e irradiação de valores. A dinâmica de concentração e dispersão cria e recria centralidades que irão ocupar e valorar diferentemente e diferencialmente territórios no tecido urbano e na dimensão da rede urbana e se traduzem em segmentação de usos e não usos e na fragmentação socioespacial. (WHITACKER, 2007, p.1).

Conforme o autor, que aborda a centralidade nas escalas intra e interurbanas, a articulação entre os diversos centros urbanos ocorre por meio da densidade dos fluxos que, por sua vez, estabelece estruturações, hierarquizações e especializações funcionais na rede urbana.

Corrêa (2001) destaca que nas últimas décadas a rede urbana brasileira ganha complexidade com a percepção de múltiplos circuitos com interações entre centros de regiões funcionais distintas, entre centros da mesma hinterlândia metropolitana e muitas interações marcadas por complementaridade funcional entre centros ou por relações que não são aquelas definidas pela Teoria dos Lugares Centrais.

$\mathrm{Na}$ realidade atual, as relações entre as cidades apresentam justaposições de relações próximas e distantes nas diferentes escalas, seja elas local, nacional, global ou as suas combinações. Ao repensar atualmente a rede urbana ganham força a complexidade da relação entre as cidades, entre cidade e campo, entre empresas. Para isso é fundamental a contribuição de Santos e Silveira (2001) já que tais autores consideram que no período atual (técnico, científico e informacional) os sistemas de cidades participam do jogo entre o local e o global.

\subsection{Aspectos teórico-conceituais sobre os fluxos aéreos}

As trocas de bens e serviços num processo de interação espacial configuram redes urbanas nas mais diversas modalidades materializadas no espaço geográfico. Os sistemas de transportes ferroviário, rodoviário, marítimo ou aéreo viabilizam fluxos urbanos cada vez mais dinâmicos e complexos. $O$ transporte aéreo vem se expandindo no Brasil, a demanda por esse setor gera fluxos e deslocamentos espaciais numa complexidade de interações. 
O estudo das redes urbanas no Brasil considerando o fluxo aéreo revela uma nova dinâmica espacial na configuração do espaço geográfico nacional em tempos de revolução nos meios de transportes, comunicação e fluxos de capital, pessoas, mercadorias, bens e serviços.

A Geografia, ciência que analisa o espaço, é fundamental para a compreensão das dinâmicas espaciais inerentes aos fluxos e fixos derivados do setor aéreo das cidades brasileiras. O transporte aéreo de passageiros vem adquirindo relevâncias socioeconômica e científica, daí a necessidade de produção do conhecimento nessa temática.

Castello Branco (2006), com base em dados de fluxos aéreos do Departamento de Aviação Civil/DAC, investigou o papel de intermediação que as cidades médias exercem na sua área de influência. A autora considerou as cidades que tinham tamanho mínimo de 100 mil habitantes e que possuíam linhas aéreas regulares. Para essa análise do indicador do fluxo aéreo, as ligações aéreas, em valores absolutos, foram distribuídas em nove classes. Em Minas Gerais foram classificadas Governador Valadares, Montes Claros, Patos de Minas, Poços de Caldas, Uberaba e Varginha. Para Montes Claros foi atribuída a classe 5, considerando a sua população urbana em 2000 (nível de 200.000 a 499.999 hab.) com 5.000 a 19. 999 ligações aéreas. Demonstrou, por meio das ligações aéreas, como estas são necessárias para a articulação da cidade média com os níveis superiores da hierarquia urbana nacional, e que esse é um setor indispensável para a existência de fluxos. Nesse cenário, Montes Claros já demonstrava desempenhar o papel de intermediação entre as diferentes escalas de centro da rede urbana.

Ainda nessa perspectiva, Alves Diniz e Alvarenga Diniz (2006) analisaram a intensidade e a direção dos fluxos aéreos oriundos e destinados aos principais aeroportos de Minas Gerais, contabilizando e mapeando a movimentação de passageiros, cargas e aeronaves. Com isso, os autores identificaram as áreas de influência dos principais aeroportos, bem como a importância econômica dos mesmos para o processo de desenvolvimento do Estado. 
Dentre as recentes transformações ocorridas no setor aeroviário em Minas Gerais, os autores diagnosticaram que

\begin{abstract}
Além dos aeroportos de Belo Horizonte, outros aeroportos vêm cumprindo importante papel na geografia dos transportes de Minas Gerais, encontrando-se localizados em importantes cidades médias do Estado, com destaque para Montes Claros, Uberlândia e Uberaba. Estes aeroportos intermediam importantes ligações econômicas para Minas Gerais, encontrando-se localizados em posições geográficas de destaque, e apresentando significativo crescimento na movimentação de aeronaves, cargas e passageiros. (ALVES DINIZ, ALVARENGA DINIZ, 2006, p.36).
\end{abstract}

O estudo desenvolvido pelo IBGE, denominado Região de Influência das Cidades/REGIC (2007) é uma importante contribuição para a análise de Rede Urbana e suas Regiões de Influência no Brasil. A pesquisa identificou os núcleos de gestão do território e delimitou sua área de influência, investigando a conformação da rede urbana e sua hierarquia. Para isso, considerou um grande número de indicadores e variáveis para a classificação das cidades nos diferentes níveis da hierarquia urbana. As cidades foram classificadas por nível de centralidade em quesitos como: gestão federal; gestão empresarial; comércios e serviços; instituições financeiras; ensino superior; saúde; internet; redes de televisão aberta e conexões aéreas.

Quanto às conexões aéreas em Montes Claros, identificou-se a importante dinâmica que a consolida nesse setor associada a centralidade que abriga em infraestruturas diversas, equipamentos, comércios e outras formas de prestação de serviços no Norte de Minas.

Pereira e Ferreira (2012) discutiram o crescimento das atividades produtivas e comerciais na mesorregião Norte de Minas, ampliando as relações econômicas entre esta região e os demais mercados nacionais e internacionais. Analisaram a configuração espacial das redes de transportes responsáveis pelo escoamento das exportações do setor siderúrgicometalúrgico destinadas ao mercado internacional, enfocando a região Norte de Minas, no período entre 2004 e 2011. Os autores sinalizaram a importância dos diversos tipos de transportes para o dinamismo das atividades econômicas e, ainda, os pontos estratégicos econômicos selecionados. 


\section{REDE URBANA E NOVAS INTERAÇÕES ESPACIAIS EM CIDADES MÉDIAS: UMA ANÁLISE ACERCA DO FLUXO AÉREO NO AEROPORTO MÁRIO RIBEIRO EM MONTES CLAROS/MG}

As mercadorias exportadas foram transportadas exclusivamente por transporte rodoviário no percurso nacional; consequentemente, os portos, aeroportos e pontos de fronteiras articulados ao transporte marítimo, aéreo e rodoviário internacional viabilizaram os fluxos das exportações. [...] A infraestrutura das redes de transportes tem seus reflexos no ordenamento espacial das atividades econômicas na mesorregião norte de Minas Gerais, uma vez que é observada uma concentração das atividades econômicas nos pontos dinâmicos e estratégicos no território norte-mineiro, principalmente naquelas áreas de mais fácil conexão com o mercado nacional e internacional. (PEREIRA, FERREIRA, 2012, p.87,89).

Pereira e Silveira (2008) analisaram a configuração do transporte aéreo regional nas cidades médias do estado de São Paulo, bem como a atuação das companhias aéreas, contribuindo para a intensificação das interações espaciais. Os autores destacaram essa modalidade de transporte no processo de produção do espaço urbano possibilitando a fluidez material e imaterial em várias escalas geográficas nos cenários internacional e nacional.

O transporte aéreo revela-se como um meio pelo qual a sociedade mantém suas relações sociais e econômicas, e é neste âmbito que se entende 0 setor como fator de mobilidade material e imaterial no espaço onde o capital se reproduz. (PEREIRA, SILVEIRA, 2008, p.38).

Azevedo e Ortigoza (2008) estudaram a crescente importância da infraestrutura aeroportuária para a dinâmica urbana das cidades, apontando os impactos socioespaciais mais relevantes nas áreas do entorno do Aeroporto Leite Lopes na cidade de Ribeirão Preto, estado de São Paulo. Os autores identificaram questões sociais, econômicas e políticas associadas à urbanização da área do entorno do aeroporto no processo de internacionalização do mesmo. Consideraram que as ações de planejamento aeroportuário, preparação orçamentária, seleção das cidades ou regiões e elaboração dos projetos são também fatores econômicos que intervêm paralelamente aos aspectos políticos.

Costa Santos (2012) apresentou algumas particularidades da articulação espacial da denominada Amazônia Setentrional Amapaense (ASA), sobretudo, a partir da dinâmica da urbanização do estado do Amapá e da estruturação de sua rede urbana. Para isso, o autor considerou quatro eixos estruturadores de análise, sendo eles: urbanização e rede urbana na Amazônia, urbanização 
concentrada na ASA, centralidade urbana de Macapá-Santana e a rede urbana de pequenas cidades. Quantos aos fluxos na rede urbana referente as conexões aéreas seus estudos demonstram que

[...] o transporte aéreo para a ASA, que diante da ausência de rodovias para uma conexão intra-regional, passou a ganhar muita importância como meio de acessibilidade a essa região. A Amazônia segue a tendência nacional quanto ao aumento do número de pessoas que passaram a utilizar o transporte aéreo, que ocorreu, sobretudo, pela relativa diminuição do preço das tarifas, acesso ao crédito e concorrência entre as empresas do ramo. Em relação à Amazônia Setentrional Amapaense, existe ainda o condicionante de relativo isolamento geográfico por via terrestre, e uma viagem fluvial de duração média de um dia a partir de Belém/PA. Tal realidade somada à conjuntura anterior, certamente contribui para aumentar a demanda de passageiros no uso do transporte aéreo para sair e chegar à região. (COSTA SANTOS, 2012, p.120).

Nesse contexto, a análise de redes urbanas a partir do transporte aéreo, revela a origem e destino dos fluxos de pessoas, os motivos dos deslocamentos, enfim, o dinamismo do setor por meio das cidades centrais que acolhem pessoas, mercadorias, capitais, bens, serviços e atividades concentradoras e dispersoras no espaço geográfico. O transporte aéreo viabiliza o funcionamento das atividades econômicas e também os fluxos de bens e serviços.

As cidades médias configuram-se como nós estruturadores dessa rede, tornando-se um foco de atração, de geração e de distribuição dos fluxos que, consequentemente, viabilizam a circulação de pessoas, de bens e de serviços pelas redes. Essas cidades através das redes de transportes conectam e interconectam um conjunto de ligações promovendo interações espaciais que atingem simultaneamente fronteiras local, regional, nacional e global.

3.3 Os fluxos aéreos em Montes Claros: a consolidação de sua centralidade $e$ as novas interações espaciais na rede urbana

O Norte de Minas possui uma área territorial de 128.602 km². (IBGE, 2010). O município de Montes Claros está situado na Bacia do Alto Médio São 
Francisco ao Norte do Estado de Minas Gerais ${ }^{4}$, possuindo uma área territorial de $3.576,76 \mathrm{~km}^{2}$ e 361.971 habitantes, a 6ª maior população do Estado com taxa de urbanização de 95,2\%. (IBGE, 2010). O PIB total de Montes Claros, conforme o IBGE (2013) é de R \$7,05 bilhões, sendo 69\% composto pelo setor de Serviços, 28\% Indústria e 3\% Agropecuária, a 10 $0^{\text {a }}$ maior economia do Estado.

Ao estudar a região Norte de Minas, Pereira (2004) entende esse recorte como produto de processos econômicos, políticos e sociais, constituindo importante meio para explicar diferentes padrões de organização espacial.

Montes Claros é classificada como cidade média conforme demonstraram os estudos de Andrade; Lodder (1979); Amorim Filho, Bueno e Abreu (1982); Pereira, Lemos(2004) e Pereira (2007); França (2007, 2012);

No final da década de 1970, Andrade e Lodder (1979) identificaram Montes Claros como uma cidade média, tendo como critério a sua dinâmica populacional. Considerando o sistema de cidades brasileiras, os autores definiram como cidades médias aquelas que, naquela década, possuíam entre 50 mil e 250 mil habitantes.

Amorim Filho e Abreu (1982) desenvolveram um estudo sobre a hierarquia das cidades médias em Minas Gerais. A partir de 25 variáveis foram definidos quatro níveis para as cidades médias mineiras: Grandes Centros Emergentes (Nível 1), Cidades Médias de Nível Superior (Nível 2), Cidades Médias Propriamente Dita (Nível 3) e Centros Urbanos Emergentes (Nível 4). Montes Claros foi classificada no referido estudo como Cidade Média de Nível Superior

[...] cidade que desenvolve paralelamente à indústria, dinâmicos setores de comércio e de serviços. Essa cidade além de fortalecer sua posição e sua relação de domínio regional, começa estender suas ligações a pontos situados além desse domínio. É uma cidade de estruturas bem consolidadas e cujo crescimento futuro, parece,

\footnotetext{
${ }^{4}$ A posição geográfica de Montes Claros também reflete na sua centralidade. Montes Claros se encontra distante geograficamente de grandes centros econômicos do país como São Paulo (983 km), Rio de Janeiro (856 km), Brasília-DF (694 km), Salvador (1.024 km) e Belo Horizonte $(428 \mathrm{~km})$. É classificada pelo plano rodoviário nacional como o segundo maior entroncamento rodoviário do país. O município é cortado pelas rodovias federais BR 135, BR 365 e BR 251; e pelas estaduais MG 308 e MG 122.
} 
sem dúvida, bem assegurado. (AMORIM FILHO E ABREU, 1982, p.41-44).

Estudos recentes, como Pereira e Lemos (2004), também qualificam essa cidade como média no estado de Minas Gerais, tendo por base a sua capacidade de polarização intra-regional. Para esses autores, o Norte de Minas tem Montes Claros como meso-polo.

Também estudos de pesquisadores regionais analisaram Montes Claros como cidade média a partir de diversas variáveis. A compreensão do significado de Montes Claros na região Norte de Minas, através dos fixos e da rede de fluxos que nela ocorrem, foi realizada por Pereira (2007). França (2007) analisou a posição de Montes Claros como cidade média no Norte de Minas Gerais, com ênfase nas novas centralidades urbanas. A mesma autora analisou na esteira dos estudos interurbanos, a natureza e a intensidade dos fluxos existentes entre a cidade média de Montes Claros e os municípios do seu entorno e, com isso, a configuração do processo de aglomeração urbana descontínua de Montes Claros/MG. (FRANÇA, 2012).

A rede urbana norte mineira, da qual Montes Claros é o centro principal, se materializa a partir da autonomia exercida por essa cidade média nas interações socioeconômicas com as diversas cidades que a compõe, além de ligações inter-regionais o que contribui para a concentração da urbanização nessa cidade. O seu dinamismo tem atraído significativas atividades terciárias, tais como comércios especializados, prestação de serviços de saúde de alta complexidade e educação superior e tecnológica ${ }^{5}$; além disso, indústrias dos ramos: têxtil, biotecnológico, alimentício, calçados, mineração não metálica (calcário) e produção de cimento; contribuindo assim para o seu desenvolvimento e crescimento.

Verificam-se, ainda, grandes investimentos direcionados ao segmento imobiliário da cidade e à construção civil, no intuito de atender à demanda das classes de alta, média e baixa renda. As construções de condomínios fechados

\footnotetext{
5 Com destaque para a Universidade Estadual de Montes Claros (UNIMONTES), a Universidade Federal de Minas Gerais (UFMG), o Instituto Federal do Norte de Minas Gerais (IFNMG), faculdades privadas (Facit, Funorte, Ibituruna, Santo Agostinho, Pitágoras, Unipac, Unopar).
} 


\section{REDE URBANA E NOVAS INTERAÇÕES ESPACIAIS EM CIDADES MÉDIAS: UMA ANÁLISE ACERCA DO FLUXO AÉREO NO AEROPORTO MÁRIO RIBEIRO EM MONTES CLAROS/MG}

e conjuntos habitacionais ou habitações populares, impulsionam a expansão urbana $^{6}$, vinculada ao processo de acumulação e de reprodução do capital. Trata-se de uma reprodução socioespacial e econômica característica da atual fase de urbanização vivenciada por Montes Claros. Assim, esta cidade confirma a sua centralidade no Norte de Minas, ao reunir funções econômicas, políticas e infraestruturais importantes, induzindo os fluxos de pessoas, mercadorias, bens e capitais. (FRANÇA, 2012).

No estudo desenvolvido pelo IBGE, denominado Região de Influência das Cidades/REGIC (2007), Montes Claros foi classificada como Capital Regional $\mathrm{B}^{7}$, integrante da Rede Urbana de Belo Horizonte que é composta por um total de 698 municípios, representando 9,1\% da população e 7,5\% do PIB do país. (REGIC, 2007).

O REGIC (2007) identificou um total de 70 Capitais Regionais (Subdivididas em Capital Regional A, Capital Regional B e Capital Regional C), com medianas de 71 mil habitantes e 71 relacionamentos ${ }^{8}$. Fazem parte da rede de Belo Horizonte as capitais regionais $B$ de Juiz de Fora (também ligada ao Rio de Janeiro) e Montes Claros; as capitais regionais $\mathrm{C}$ de Divinópolis, Governador Valadares, Ipatinga-Coronel Fabriciano-Timóteo, Teófilo Otoni, Varginha e Uberaba (também ligada a São Paulo); os centros sub-regionais A de Barbacena, Muriaé, Ubá, Patos de Minas, Lavras, Manhuaçu, Passos e Ponte Nova e os centros sub-regionais B Cataguases, Janaúba, Caratinga, São Lourenço, Viçosa, Conselheiro Lafaiete e São João Del Rei. (IBGE, REGIC, 2007, p.14)

\footnotetext{
${ }^{6}$ Cf. FRANÇA, lara Soares de; ALMEIDA, Maria Ivete Soares de. O processo de verticalização urbana em cidades médias e a produção do espaço em Montes Claros/MG. Boletim Gaúcho de Geografia, v. 42, n.2, 2015. Versão online disponível em: http://www.seer.ufrgs.br/index.php/bgg/article/view/52944/34038

${ }^{7}$ Os pesquisadores de cidades médias adotam vários critérios para a sua análise, tais como: tamanho populacional, grau de urbanização, características funcionais, centralidade, qualidade de vida urbana, relevância regional, posição estratégica e desempenho econômico. O REGIC (2007) hierarquizou os centros urbanos e as suas regiões de influência por meio de fluxos diversos. Assim, esse estudo considera, notadamente, as funções desempenhadas pelas cidades a partir da concentração de bens e serviços. Montes Claros, classificada como Capital Regional B, se insere nesse contexto pelo papel regional que desempenha no Norte de Minas.

${ }^{8}$ Conforme o IBGE (2007) o REGIC tem como objetivo "conhecer os relacionamentos entre as cidades brasileiras com base na análise dos fluxos de bens e serviços", dessa forma, a intensidade dos relacionamentos explicita a dimensão dos fluxos de bens e serviços entre as cidades.
} 


\section{REDE URBANA E NOVAS INTERAÇÕES ESPACIAIS EM CIDADES MÉDIAS: UMA ANÁLISE ACERCA DO FLUXO AÉREO NO AEROPORTO MÁRIO RIBEIRO EM MONTES CLAROS/MG}

As capitais regionais foram definidas pelo IBGE (REGIC, 2007) como aquelas que exercem forte polarização na região em que se localiza, influenciando as pequenas e as médias cidades, bem como as áreas rurais ao seu entorno.

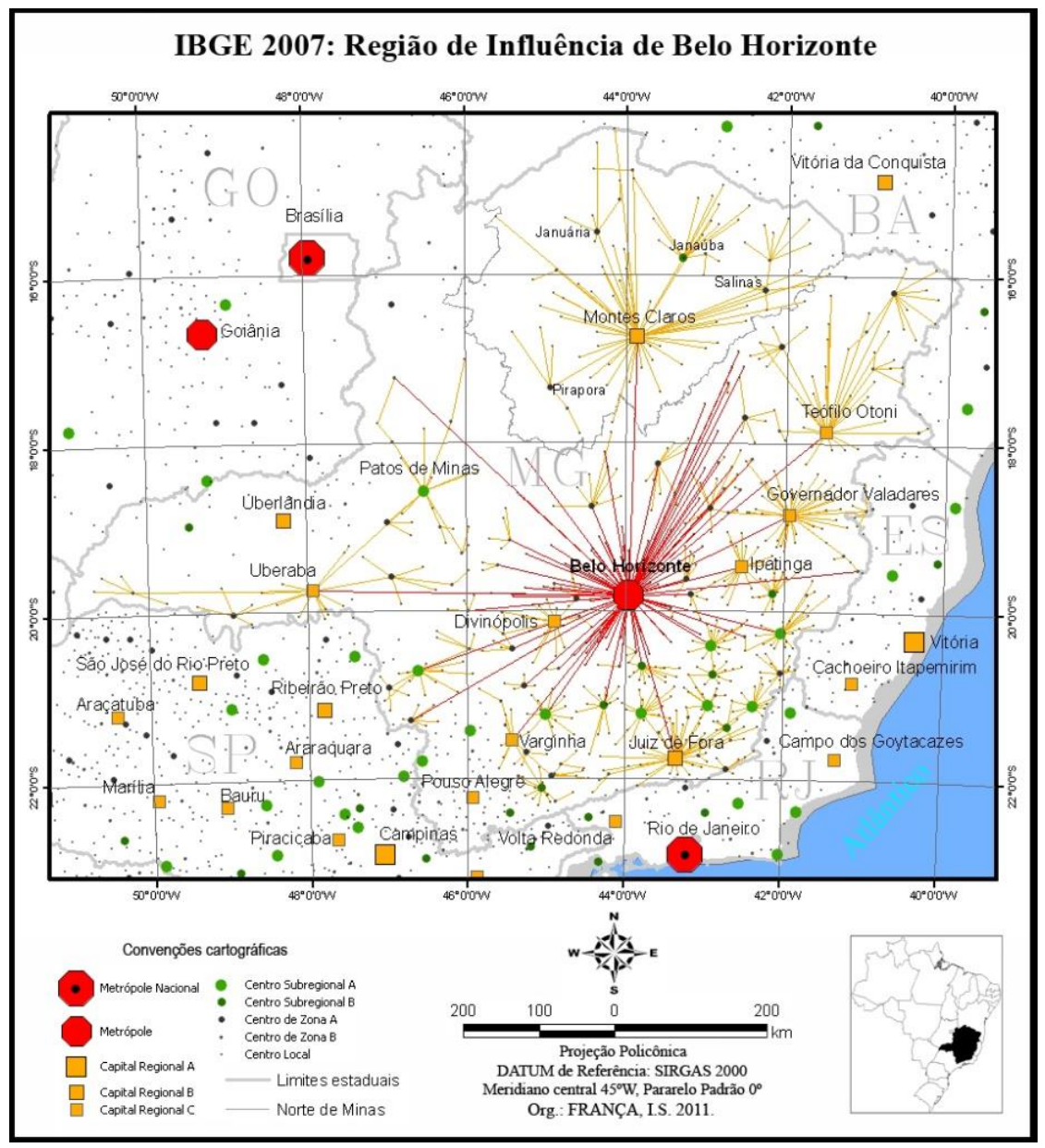

Figura 1: Região de Influência de Belo Horizonte, 2007 Fonte: IBGE, 2007.

Conectada à Região de Influência de Belo Horizonte, Montes Claros exerce forte centralidade na região Norte de Minas, envolvendo 89 municípios, além dos vales do Jequitinhonha e Mucuri e Sul da Bahia. Dentre os centros do Norte de Minas pertencentes à Região de Influência de Belo Horizonte, têm-se, ainda, Janaúba (Centro Sub-regional B), Januária, Pirapora e Salinas (Centros de Zona A), e Itacarambi, Manga, Porteirinha, São Francisco, Taiobeiras e Várzea da Palma (Centros de Zona B) (IBGE, 2007, p.94).

As cidades que possuem as atividades econômicas e funções urbanas mais desenvolvidas e modernas são estratégicas na organização do território, 
exercendo papel central na rede urbana em que se inserem. Com isso, sua localização é relevante, mas deve estar associada ao seu papel econômico central. A concentração desses elementos (fixos) culminará em fluxos diversos e, com isso, na centralidade urbana.

Sendo assim, a posição hierárquica de uma cidade na rede em que se insere resulta de seu perfil econômico, associado à concentração de atividades produtivas, riquezas, população, infraestruturas, serviços alocados e, principalmente, de sua capacidade de absorção de investimentos públicos e privados. A concentração espacial desses elementos fomenta as relações entre as cidades; dessa forma, tais elementos podem definir a polarização a favor das metrópoles e das cidades médias, a subordinação de centros de menor dinamismo e, ainda, a competição entre as cidades da rede. A análise da rede urbana por meio dos fluxos aéreos ilustra o dinamismo de tais interações.

O Aeroporto Mario Ribeiro está localizado a aproximadamente $7 \mathrm{~km} \mathrm{da}$ área central de Montes Claros. É administrado pela Infraero desde 1980 e possui uma pista de pouso de 45 metros de largura e 2.100 metros de extensão. (INFRAERO, 2015). Duas companhias aéreas operam neste aeroporto: A AZUL Linhas Aéreas e a GOL Linhas Aéreas.

Os resultados obtidos com a pesquisa no sitio eletrônico da Infraero referente aos anos de 2013 e 2014 apontaram que os fluxos (embarques e desembarques) de passageiros na cidade nos meses de janeiro a setembro foram bastante intensos. Registrou-se um aumento de 8,5\% na quantidade de passageiros transportados, num total de 355.669 pessoas. O aeroporto Mario Ribeiro em Montes Claros foi o segundo do interior do Estado de Minas Gerais que mais transportou passageiros em 2014. Apenas o Aeroporto de Uberlândia movimentou mais passageiros. (Infraero, 2015).

Comparativamente, no ano de 2014, o aeroporto de Montes Claros movimentou o equivalente a $38 \%$ do total de passageiros transportados através do aeroporto da Pampulha em Belo Horizonte. 


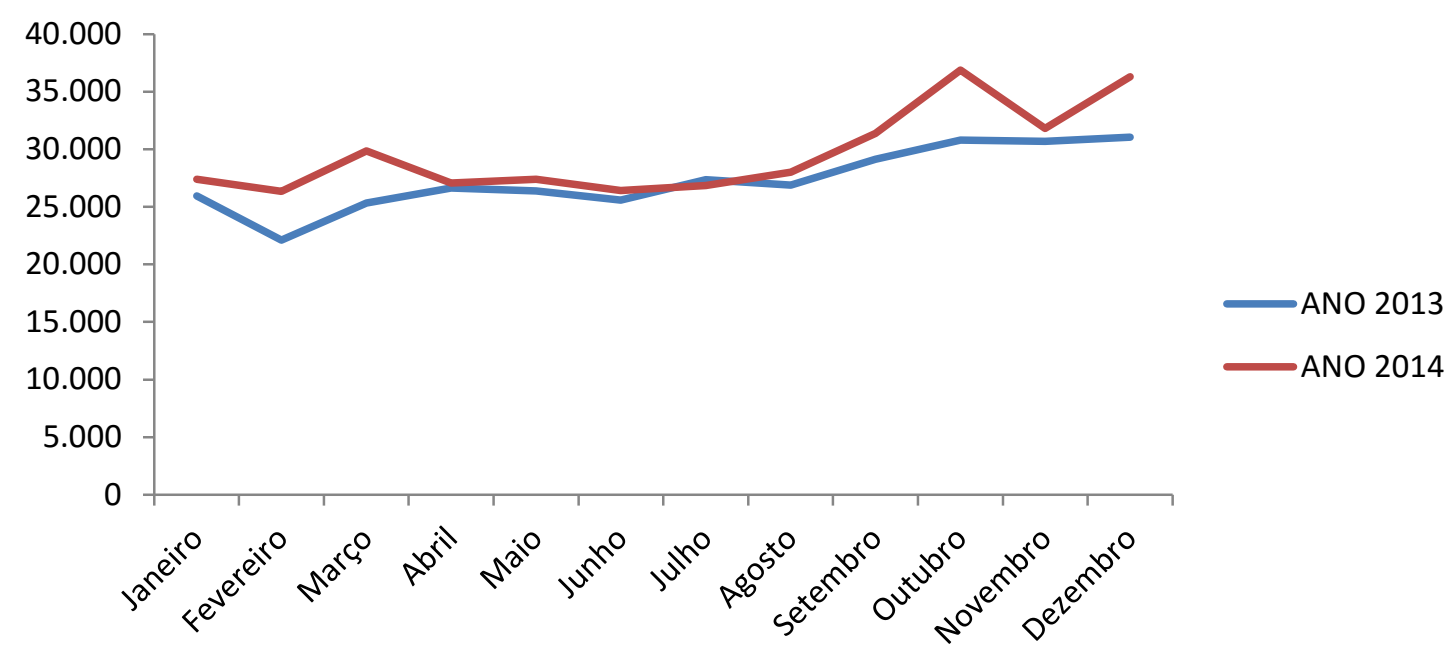

Gráfico 1: Passageiros transportados (embarques e desembarques) no Aeroporto Mario Ribeiro na cidade média de Montes Claros/MG, 2013-2014.

Fonte: INFRAERO, 2015

Org.: FRANÇA, I. S.,2015.

O gráfico 1 possibilita afirmar que o fluxo aéreo no referido aeroporto tem simetria mensal, não se observa picos de passageiros transportados em determinados períodos do ano. Assim, não se trata de fluxo sazonal, comum em aeroportos do interior do país, quando o fluxo de passageiros se acentua nos períodos de férias (julho e janeiro).

Ratificando o dinamismo de Montes Claros nas redes de ligações aéreas, o REGIC (IBGE, 2007, p 161) destacou que "o transporte aéreo coloca Montes Claros com um importante polo regional nesse setor", pois a centralidade desse serviço faz com que indivíduos se desloquem de outros municípios para Montes Claros para usufruir desse transporte.

O público que o aeroporto atende é composto, sobretudo, por empresários, médicos, advogados, políticos, turistas, técnicos, professores e estudantes que utilizam esse transporte para se deslocarem com maior facilidade e em um curto espaço de tempo para os grandes e médios centros urbanos do país. Montes Claros polariza o atendimento ou a demanda de consumo de transporte aéreo na região sendo a única cidade no Norte de Minas a possuir um aeroporto. Nesse sentido, o acesso entre os municípios nortemineiros a Montes Claros, bem como, para outros estados e regiões do país, é 
facilitado pela infraestrutura dos meios de transportes, o que contribui com o movimento populacional constante entre os municípios.

A infraestrutura das estradas e os meios de transportes oferecidos à população faz com que as mobilidades populacionais aumentem no território. Castello Branco et al (2005) atribuem a questão do transporte a uma realidade no aumento dos movimentos pendulares, onde os deslocamentos diários podem ser facilitados com os transportes. As autoras comentam que "A principal causa desse aumento seria a melhoria no sistema de transportes [...] que possibilita a elevação das distâncias percorridas diariamente”. (Castello Branco et al , 2005, p 05).

Outras variáveis foram analisadas, a fim de compreender a centralidade exercida pela cidade média de Montes Claros no setor aéreo. A partir de entrevistas realizadas no Aeroporto Mário Ribeiro de Montes Claros, identificou-se os motivos dos deslocamentos de passageiros, além da origem e destino dos fluxos. (Mapas 1 e 2). 


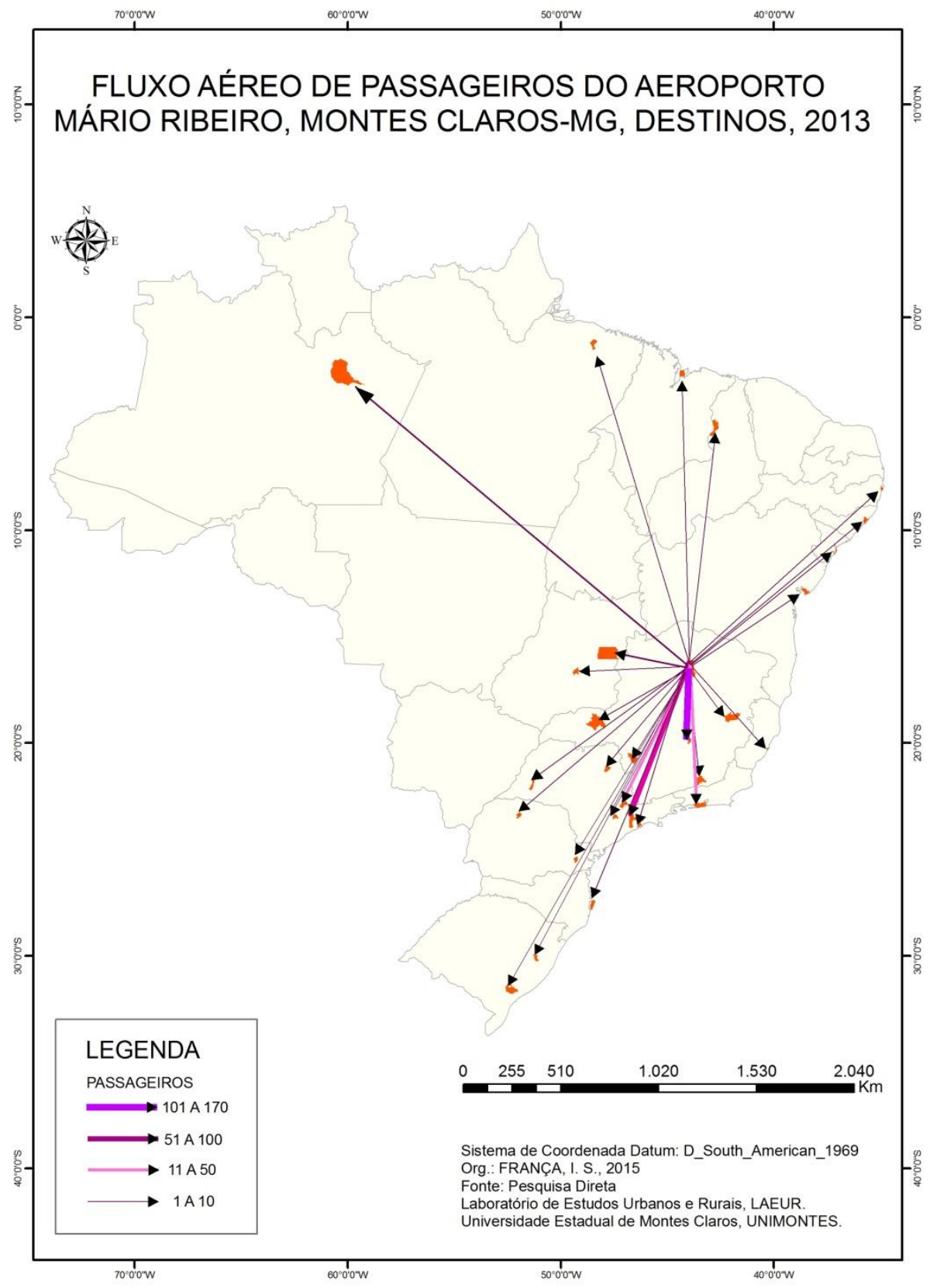

Mapa 1 - Destino dos passageiros que embarcaram no Aeroporto Mário Ribeiro em Montes Claros, 2013.

Quanto aos destinos dos passageiros que embarcaram no Aeroporto em Montes Claros destaca-se Belo Horizonte (43\%), São Paulo (26\%), Rio de Janeiro (10\%), Campinas (6\%) e Brasília (3\%). Importa ressaltar, também, o fluxo em direção às diversas regiões do país, tais como Norte, Nordeste e Sul. 


\section{MOTIVO EMBARQUE}

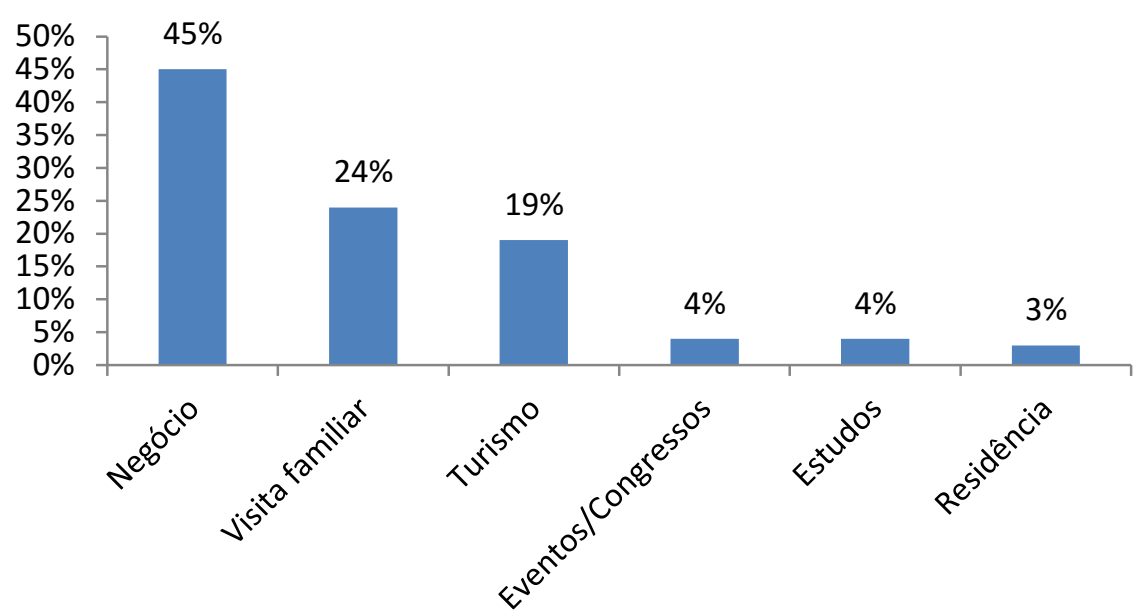

Gráfico1: Aeroporto Mário Ribeiro de Montes Claros, MG: Motivo do embarque, nov.2013. Fonte: Pesquisa Empírica, 2013. Org.: FRANÇA, 2015.

O principal motivo das viagens realizadas pelos passageiros que embarcaram no Aeroporto de Montes Claros foi negócios (45\%), seguido de visita familiar (24\%) e turismo (19\%). Assim, negócios e turismo configuram $64 \%$ da motivação das viagens. 


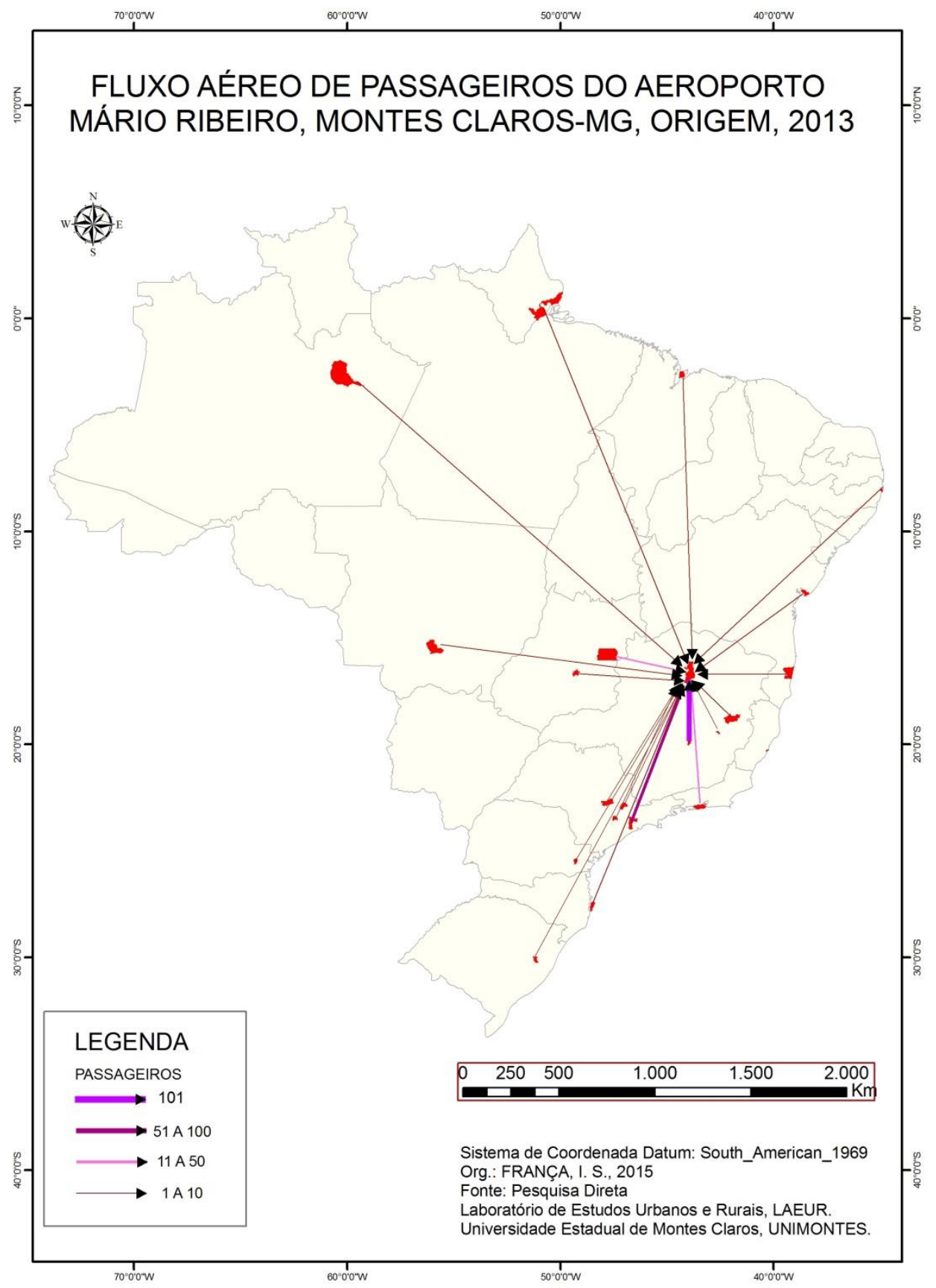

Mapa 2 - Origem dos passageiros que desembarcaram no Aeroporto Mário Ribeiro em Montes Claros, 2013.

Quanto às origens dos passageiros que desembarcaram no Aeroporto em Montes Claros destaca-se Belo Horizonte (44\%), São Paulo (28\%), Brasília $(9 \%)$, Rio de Janeiro (6\%), Campinas (3\%). Ressalta-se, também, a origem de diversas regiões do país, tais como Norte, Nordeste e Sul. 


\section{MOTIVO DESEMBARQUE}

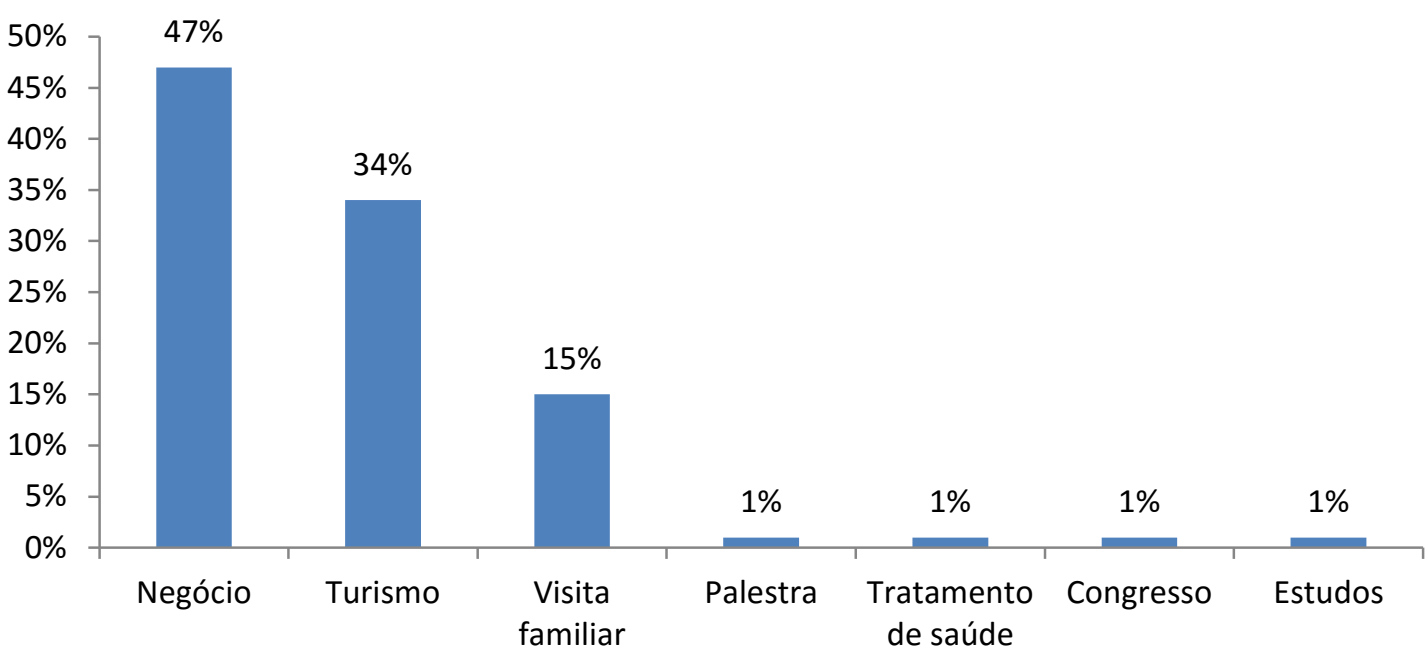

Gráfico 2: Aeroporto Mário Ribeiro de Montes Claros, MG: Motivos do desembarque, nov.2013. Fonte: Pesquisa Empírica, 2013. Org.: FRANÇA, 2015.

Diagnosticou-se os principais motivos das viagens dos passageiros que desembarcaram em Montes Claros: negócios (47\%), turismo (34\%) e visita familiar (15\%). Nesse caso, negócios e turismo configuram $81 \%$ da motivação das viagens. Assim, é um turismo de negócios, em decorrência da polarização industrial e terciária (educação superior e saúde de alta complexidade), com realização frenquente de congressos, seminários, feiras e exposições.

Belo Horizonte e São Paulo concentram $70 \%$ dos fluxos de embarque e desembarque no Aeroporto Mário Ribeiro em Montes Claros. Esta constatação dos fluxos de passageiros entre Montes Claros, Belo Horizonte e São Paulo, associado às motivações das viagens concentradas em negócios e turismo, se explica por se tratar da capital do Estado e do principal centro industrial e financeiro do país.

Os motivos para embarque e desembarque apontados pelos entrevistados revelam a importância do setor aéreo para o dinamismo das economias urbanas. Sabe-se que transporte aéreo é um setor de prestação de serviços que envolve atividades que permite o transporte de passageiros e de cargas. Dessa forma, as cidades, por sua vez, consolidam-se como os polos centrais de realização das atividades econômicas. Elas conformam com isso, a 
organização das redes geográficas, manifestando as interações espaciais através de um espaço dialético de fixos e de fluxos.

Os dados de fluxos aéreos apresentados demonstram as modificações na rede urbana brasileira atual expostas por Corrêa (2001), como a continuidade da criação de novos núcleos urbanos, a crescente complexidade funcional dos centros urbanos já existentes, a mais intensa articulação entre centros e regiões, a complexidade dos padrões espaciais da rede e as novas formas de urbanização.

Conforme retratado nos mapas 1 e 2 , na rede urbana norte mineira as interações espaciais se materializam também por meio dos fluxos aéreos que conectam Montes Claros, cidade central na rede urbana regional às escalas superiores da rede urbana brasileira. Isto é, o transporte aéreo regional interliga cidades médias ou localidades interioranas com centros urbanos/capitais, estabelecendo, assim, a intensidade das relações sociais e econômicas.

Os resultados expostos permitem, nesse sentido, compreender as interações urbanas além das trocas, sejam elas hierárquicas, complementares, ou não. Milton Santos (1996) desenvolveu as noções ou os conceitos de horizontalidades e verticalidades. Estes fazem referência à contiguidade ou não dos espaços numa única unidade regional, podendo, dessa forma, auxiliar na análise de interação de municípios, ou seja, nos processos de aglomeração e redes urbanas.

A horizontalidade é trabalhada pelo autor na perspectiva de ampliação da coesão da sociedade, quer seja através do interesse coletivo ou da produção e não apenas dos fluxos econômicos. Portanto, relaciona-se com a contiguidade ou a interligação de pontos no espaço, o intercâmbio ou as relações socioeconômicas entre o local e o seu entorno. Refere-se ainda, a espaços vizinhos reunidos por uma continuidade territorial ou as relações socioeconômicas entre os habitantes de uma determinada área geográfica. (SANTOS, 1996).

As verticalidades, por sua vez, são "os vetores da integração hierárquica regulada". (SANTOS, 1996, p.54), tendo como eixo integrador dos espaços a circulação de produtos, mercadorias e informações. O autor enfatiza as 
relações verticais estabelecidas no âmbito da escala do local para a global. Os pontos distantes uns dos outros são ligados verticalmente por processos e formas espaciais. As redes de cidades e as interações entre elas se materializam em lugares contínuos e não contínuos, mas com funcionalidades diferentes. Verticalidades e horizontalidades se entrecruzam e se complementam culminando em redes urbanas cada vez mais complexas e dinâmicas.

Do ponto de vista da estruturação da rede urbana, o setor aéreo pode ser concebido como um eixo articulador de fluxos de pessoas e produtos que contribui para o desenvolvimento regional, como é o caso da cidade média de Montes Claros, favorecendo a intensificação das interações espaciais que resultam da fluidez no território. Como abordado por Corrêa (2001) há um estreito relacionamento entre os meios de transportes, como o aéreo, e a urbanização.

\section{CONSIDERAÇÕES FINAIS}

No Brasil o crescente processo de urbanização consolidado após a $2^{a}$ metade do século XX provocou alterações importantes na dinâmica econômica, política e social do país com efeitos no espaço geográfico, destacando-se a reestruturação da Rede Urbana Brasileira. Nesse contexto, o fenômeno urbano no Brasil nas últimas décadas revelou um novo padrão de urbanização. Até meados da década de 1970 o processo de urbanização teve nas metrópoles nacionais a base quase que exclusiva de sua articulação e reprodução. Após esse momento, com a desconcentração econômica e industrial metropolitana, configura-se a emergência das cidades médias como importantes centralidades no país.

Montes Claros é, atualmente, o maior centro urbano da região Norte de Minas. Seu alto potencial econômico deriva da dinamicidade dos setores de comércios e prestação de serviços e também do desenvolvimento das atividades industriais. Montes Claros é considerada uma cidade média devido a esses fatores, o que ratifica a sua influência nas cidades circunvizinhas que 
compõe a região Norte de Minas, além de interações diversas inter-regionais o que evidencia maior autonomia e as novas conexões na rede urbana.

Diversos fatores como a instalação de novas indústrias, a concentração e diversificação de instituições de ensino superior e técnico, grandes redes de supermercados varejistas e atacadistas, hipermercados, shopping centers e serviços especializados, entre outras estruturas, têm contribuído ainda mais para o dinamismo econômico dessa cidade.

Com isso, o desenvolvimento dessas atividades econômicas aliado à ampliação do consumo da população, ratifica a centralidade dessa cidade média e a expansão de sua hinterlândia, proporcionada também pelos sistemas de transportes e comunicação. Montes Claros mantém relações de proximidade com os núcleos urbanos da região Norte de Minas, sobrepondo uma rede de relações com outras regiões, conformando um sistema regional.

Nesse sentido, o presente estudo analisou a centralidade exercida pela cidade média de Montes Claros/MG, a partir dos fluxos aéreos no Aeroporto Mario Ribeiro, diagnosticados nos anos de 2013 e 2014, demonstrando sua crescente especialização funcional e outras formas de inserção na rede urbana. Assim, a análise demonstrou que:

- Montes Claros segue a tendência nacional quanto ao aumento do número de pessoas que utilizam o transporte aéreo, que ocorreu, sobretudo, pela relativa diminuição do preço das tarifas, ampliação da oferta de voos, num processo de intensificação da circulação de informações, mercadorias e pessoas. Para Harvey (2000) a atual condição pós-moderna tem como um de seus elementos mais importantes a aceleração da produção, da troca e do consumo;

- As cidades médias têm importante função na organização da circulação aérea. Isso resulta em interações espaciais onde a rede urbana regional, em constante dinamismo e com o aparato de fixos (sistema do aeroporto), representado pelo sistema aéreo de Montes Claros, promove a fluidez. Sobre isso, Egler (2006, p.215-216) ressalta "toda região possui um centro que a estrutura, e a manifestação mais concreta dos 
níveis de integração territorial em uma determinada região é a consolidação de sua rede urbana";

- O papel que Montes Claros exerce na rede urbana regional e no sistema urbano brasileiro em escalas mais amplas, a partir das interações com centros urbanos de maior complexidade. Além da histórica articulação com o espaço regional. Conforme Moreira (2006), para a grande rede de nodosidade, a cidade torna-se fundamental na tarefa, atribuída ao espaço, de integrar lugares cada vez mais articulados em rede;

- "As redes de transporte aéreo são um aspecto indissociável da rede urbana" (IBGE, 2008, p. 138), a partir de interligações espaciais de territórios contínuos e descontínuos espacialmente, propiciando condições favoráveis para a dinâmica econômica territorial e, com isso, as interações espaciais;

- Há estreita relação entre Montes Claros e Belo Horizonte, capital mineira e São Paulo, maior centro financeiro do país, respectivamente, denotando sua expressão como nó articulador das interações na rede urbana nas escalas intra e inter-regional. Chama a atenção, a centralidade de Belo Horizonte como ponto de origem ou destino final das maiorias dos voos, obedecendo nitidamente à hierarquia urbana estadual e o papel dos principais aeroportos, tais como Confins, que concentram e distribuem estrategicamente os voos para o restante do território brasileiro e para outros países;

- Existem conexões com outras cidades brasileiras e até mesmo internacionais, o que ratifica o perfil da demanda existente, uma vez que o motivo principal de viagens apontado pelos passageiros é a realização de negócios e turismo;

- Dentre os outros motivos para os deslocamentos, a visita familiar, atesta o papel do aeroporto de Montes Claros no plano regional com fluxo de pessoas, associado ao de bens, capitais e mercadorias, fomentando consumos diversos; 
- Com isso, os fluxos aéreos viabilizam a complexificação do sistema urbano em que se insere Montes Claros através da fluidez material e imaterial.

Dessa forma, o transporte aéreo em Montes Claros apresenta um constante crescimento no número de passageiros embarcados e desembarcados, fato esse que caracteriza o crescimento do setor em âmbito regional e o aumento do número de empresas aéreas operando os voos, o que contribui para as interações espaciais para e a partir dessa cidade média. Assim, atesta a importância das cidades médias como redes geográficas que possibilitam um aumento das interligações espaciais entre os territórios.

Ao analisar a centralidade exercida pela cidade média de Montes Claros/MG a partir dos fluxos aéreos no Aeroporto Mario Ribeiro, diagnosticados nos anos de 2013 e 2014, compreende-se a necessidade de se pesquisar as cidades médias através dos diferentes papéis que desempenham na rede urbana, já que se estabelecem conexões e interações espaciais processadas em decorrência das infraestruturas e dos meios de transportes.

Para Spósito (2001) as cidades médias desempenham um papel de polo, nos quais os fluxos de pessoas dos centros menores e/ou de áreas rurais direcionados a essas ampliam a sua função urbana de centro sub-regional, promovendo a própria centralidade. Esta, por sua vez, está ligada ao aspecto intra-urbano das cidades, o que redefine e amplia a sua centralidade interurbana.

Com isso, há que se debruçar sobre estudos das centralidades econômicas, políticas e infraestruturais desempenhadas pelas cidades médias, configurando a sua importância nas redes urbanas e apontando novos caminhos teóricos e metodológicos para esse campo de estudos.

\section{AGRADECIMENTOS}

Fundação de Amparo à Pesquisa do Estado de Minas Gerais - FAPEMIG 


\section{REFERÊNCIAS}

AMORIM FILHO, Oswaldo Bueno, BUENO, Maria Elizabeth Taitson; ABREU, João Figueiredo. Cidades de porte médio e o programa de ações sócioeducativo-culturais para as populações carentes do meio urbano em Minas Gerais. Boletim de Geografia Teorética, Rio Claro/SP, v. 2, n. 23-24, 1982. p. 33-46.

ANDRADE, Thompson, LODDER, Celsius. A. Sistema urbano e cidades médias no Brasil. IPEA. Rio de Janeiro: IPEA/INPES, 1979.

AZEVEDO, Júlio Cesar de; ORTIGOZA, Silvia Aparecida Guarniere. Instalação e ampliação de aeroportos e seus impactos sócio-espaciais em cidades paulistas: o caso de ribeirão preto. VII SITRAER - Simpósio de Transporte Aéreo - RJ, 26 a 28 DE Janeiro, 2008. p.709-720.

BEAUJEU-GARNIER, Jacqueline. A cidade e a organização do território. In: Geografia Urbana. 2a. edição, 1997. Fundação CalousteGulbenkian/Lisboa. Tradução Raquel Soeiro de Brito. p.457-492.

CASTELLO BRANCO, Maria Luisa. Cidades Médias no Brasil. In: SPOSITO, Eliseu Silvério; SPOSITO, Maria Encarnação Beltrão; SOBARZO, Oscar. Cidades médias: produção do espaço urbano e regional. São Paulo: Expressão Popular, 2006.

CASTELLO BRANCO, Maria Luisa. Movimento pendular e perspectivas de pesquisas em aglomerados urbanos/Commutingandresearchperspectives in urbanagglomerations, $2005 . \quad$ Disponível em: <http:lwww.scielo.br/pdf/spp/v19n4/v19n4a08.pdfhtml/>.

CHRISTALLER, Walter. Teoria das LocalidadesCentrais (1933). In: Central places in southerngermany. Englewood Cliffs: Prentice-Hall, 1966.

CORRÊA, Roberto Lobato. Construindo o conceito de cidade média. In: SPÓSITO, Maria Encarnação Beltrão (Org.). Cidades Médias: espaços em transição. 1a. ed. São Paulo: Expressão Popular, 2007. p.23-33.

CORREAA, Roberto Lobato. Estudos sobre a Rede Urbana. Rio de Janeiro: Bertrand Brasil, 2006.

CORRÊA, Roberto Lobato. Região e organização espacial. 7ª Ed. São Paulo. 2001.

CORRÊA, Roberto Lobato. Interações Espaciais. In. CASTRO, I. E.. GOMES, P. C.; CORRÊA, R. L. (Org.) Explorações Geográficas. 3 ed. Rio de Janeiro: Bertrand Brasil, 1997, p. 279-318. 
COSTA SANTOS, Emmanuel Raimundo. Urbanização e Rede Urbana na Amazônia Setentrional Amapaense/AP. Revista Formação Online, n. 19, volume 2, jul./dez., 2012. p. $107-131$.

DINIZ, Alexandre Magno Alves; ALVARENGA DINIZ, Leoni Carlos. Análise dos principais fluxos aéreos dos aeroportos da capital mineira e suas recentes transformações. Sociedade \& Natureza, Uberlândia, 18 (34): 31-43, jun. 2006.

EGLER, Claudio A. G. Questão regional e gestão do território no Brasil. In: CASTRO, Iná Elias; GOMES, Paulo Cesar da Costa; CORRÊA, Roberto Lobato (Org). Geografia: conceitos e temas. $1^{\underline{a}}$ ed. Rio de Janeiro: Bertrand Brasil, 1995.

FRANÇA, lara Soares. Aglomeração urbana descontínua de Montes Claros/MG: novas configurações socioespaciais. 2012.393fTese (Doutorado em Geografia) - Instituto de Geografia, Universidade Federal de Uberlândia, Uberlândia: UFU, 2012.

FRANÇA, lara Soares. A cidade média e suas centralidades: $O$ exemplo de Montes Claros no Norte de Minas Gerais. Instituto de Geografia, Universidade Federal de Uberlândia, (Dissertação Mestrado em Geografia) 2007. 208p.

GEIGER, Pedro Pinchas. Evolução da Rede Urbana Brasileira. Rio de Janeiro: CBPE, 1963. (Coleção o Brasil Urbano).

HARVEY, David. Condição pós-moderna: uma pesquisa sobre as origens da mudança cultural. 11ª. ed. São Paulo: Edições Loyola, 2002.

INFRAERO. <http://www.infraero.gov.br/>. <Acesso em 01 de Setembro 2011>.

INSTITUTO BRASILEIRO DE GEOGRAFIA E ESTATÍSTICA/IBGE. Região de Influência das Cidades/REGIC: Rio de Janeiro/RJ. Edições: 1987, 2007.

INSTITUTO BRASILEIRO DE GEOGRAFIA E ESTATÍSTICA/IBGE. Censo Demográfico, 2010. Disponível em <http://www.ibge.gov.brhtm/>.

INSTITUTO DE PESQUISA ECONÔMICA APLICADA - IPEA. Brasil em desenvolvimento: Estado, Planejamento e Políticas Públicas. Vol. 2. Brasilia: IPEA, 2010.

LEFEBVRE, Henri. A Revolução Urbana. Belo Horizonte: Editora: UFMG, 1999. Tradução Sergio Martins.

MATOS, Ralfo Edmundo da Silva. Espacialidade em rede: população, urbanização e migração no Brasil contemporâneo. Belo Horizonte: C/Arte, 2005. 264 p. ISBN: 85- 7623- $024-0$. 
MOREIRA, Ruy. Para onde vai o pensamento geográfico? São Paulo: Contexto, 2006.

PEREIRA, Ana Paula Camilo; SILVEIRA, Márcio Rogério. A dinâmica do transporte aéreo regional nas cidades médias do estado de São Paulo. Formação (online), vol. 2, no 15 (2008). p.37-55.

PEREIRA, Anete Marília. Cidade Média e Região: o significado de Montes Claros no Norte de Minas Gerais. Instituto de Geografia, Universidade Federal de Uberlândia. Uberlândia/MG, 2007. Tese (Doutorado).

PEREIRA, Anete Marília. A propósito das cidades médias: algumas considerações sobre Montes Claros. In: SIMPÓSIO INTERNACIONAL SOBRE CIDADES MÉDIAS, 1., 2005, Presidente Prudente. Anais... Presidente Prudente: GASPERR/UNESP, 2005. p. 1-13.

PEREIRA, Anete Marília. A urbanização no sertão norte-mineiro algumas reflexões. In: PEREIRA, Anete Marília; ALMEIDA, Maria Ivete Soares de. (Org.). Leituras Geográficas sobre o Norte de Minas Gerais. Unimontes. Montes Claros. 2004. p.11-32.

PEREIRA, Anete Marília; LEITE, Marcos Esdras. A expansão urbana de Montes Claros a partir do processo de industrialização. In: PEREIRA, Anete Marília; ALMEIDA, Maria Ivete Soares de. (Org.). Leituras Geográficas sobre o Norte de Minas Gerais. Unimontes. Montes Claros. 2004. p.33-51.

PEREIRA, Fabiano Maia; LEMOS, Mauro Borges. Cidades médias: uma visão nacional e regional. Anais do XI Seminário sobre economia mineira. Diamantina, 24 a 27 de Agosto de 2004. Disponível em http:II.www.cedeplar.ufmg.br.

PEREIRA, Luís Andrei Gonçalves; FERREIRA, Willian Rodrigues. Redes de Transportes e Comércio Internacional: os fluxos das exportações do setor siderúrgico-metalúrgico no norte de Minas Gerais. R. Ra'e Ga - Curitiba, v.29, p.64-91, dez/2013. ISSN: 2177-2738

SANTOS, Milton. Manual de Geografia Urbana. 3ª Edição. São Paulo: Edusp. 2008.

SANTOS, Milton. A Natureza do Espaço: técnica e tempo, razão e emoção. São Paulo: Hucitec, 1996.

SANTOS, Milton, SILVEIRA, Maria. L. O Brasil: Território e Sociedade no Início do Século XXI. Editora Record. Rio de Janeiro, 2001.

SPOSITO, Maria Encarnação Beltrão. Cidades médias: espaços em transição. São Paulo: Expressão Popular, 2007. 
SPOSITO, Maria Encarnação Beltrão. Novas formas comerciais e redefinição da centralidade intra-urbana. In: SPOSITO, Maria Encarnação Beltrão. (Org.). Textos e contextos para a leitura geográfica de uma cidade média. Presidente Prudente: 2001, p. 235-253.

WHITACKER, Arthur Magon. Inovações Tecnológicas, Mudanças nos Padrões Locacionais e na Configuração da Centralidade em Cidades Médias. Anais do $X$ Coloquio Internacional de Geocrítica: Los Problemas del Mundo Actual.

Soluciones $Y$ Alternativas desde la Geografía Y las Ciencias Sociales. Porto Alegre, 28 de mayo - 1 de junio de 2007. Universidade Federal do Rio Grande do Sul. 